\title{
The Lover-Beloved Relation Reconsidered
}

\author{
RICHARD HOLMES and MANO DANIEL \\ University of Waterloo
}

While Sartre claims that all human relations share the same fundamental ontological structure, the dismal picture he paints in Being and Nothingness in which he describes the lover-beloved relation as two subjectivities in conflict, is a far cry from the optimistic portrayal of the reader-writer relation as the mutual collaboration of two freedoms in What is Literature? It is tempting to explain away this incongruity by asserting either that Sartre changed his mind about human relationships, or that he is simply inconsistent. While we agree that the reader-writer relation does seem to suggest a new dimension of interaction, it is our contention that this new dimension is already prefigured in Being and Nothingness when Sartre describes the manner in which the present self confronts and integrates its history in light of its present and future projects. Sartre, we argue, was not able to carry through this analysis to his more general description of human relations because he had conflated a distinction in his description of consciousness in Transcendence of the Ego and Being and Nothingness. By reviewing and revising his account of the nature of consciousness as it stands before itself or another, as described in Transcendence of the Ego, we enable the expansion of the realm of human relationships beyond the ostensible limits prescribed in Being and Nothingness.

In Being and Nothingness, Sartre's description of the concrete relation with others as exemplified by the relation of love seems to lead to an ontological paradox:

Why should I want to appropriate the Other if it were not precisely that the Other makes me be? ... . The lover does not desire to possess the beloved as one possesses a thing; he demands a special type of appropriation. He wants to possess a freedom as freedom ... He wants to be loved by a freedom but demands that this freedom as freedom should no longer be free."'

This relationship is used to demonstrate the ontological dependence of the lover on the beloved as well as the paradoxical nature of this dependence. Partners, lovers, and, in general, individuals interact by oscillating between the antithetical poles of domination and counterdomination since: "While I attempt to free myself from the hold of the

${ }^{1}$ Jean-Paul Sartre, Being and Nothingness, (New York, 1963), pp. 366-367. 
Other, the Other is trying to free himself from mine; while I seek to enslave the Other, the Other seeks to enslave me."2

Sartre's description of human love is doubly self-defeating. This special type of appropriation requires the Other, as the object of my love, not be an automaton. The Other must preserve its autonomy in order to freely give or receive love. Yet the lover sadistically relates to the beloved by making the beloved into an object. Moreover, the lover experiences perpetual insecurity. The Other may only see the lover as an object and hence, deprive the lover of his autonomy. As such, all attempts at love, and, more generally, human interactions, remain thwarted and unfulfilled because both lover and beloved want to have each other as autonomous and as objectified which, on this account, is not possible. This paradox is succinctly summarised by the line from "No Exit,"--"Hell is other people"-which perhaps best epitomises Sartre's early view of society in which conflict is the inevitable and unenviable state of human relationships. Sartrean individuals appear as uni-dimensional creatures unable to genuinely relate to others. On this account, therefore, social relationships must ultimately be viewed as insecure, dismal, futile and doomed to a hell void of joy. Man is a "useless passion" because he cannot overcome this fundamental alienation from the Other.

By 1947, however, Sartre had come to moderate this view of human relationships, motivated, in large part, by his reflections on aesthetics and, in particular, on the pivotal role that he ascribes to reading. In What is Literature?, Sartre offers a description of the relationship between the writer and the reader which is different from the one between lovers since the writer and the reader relate cooperatively to each other. Borrowing heavily from Croce's theory of aesthetics, Sartre argues that the writer does not write for himself but rather writes for readers whose constitutive role is needed to complete the creation of the work. Just as the painter needs the spectator, the composer, the listener, the writer needs the reader to complete the work. Reading, as Sartre puts it, is the "dialectical correlative" of writing. Writing and reading necessitate two distinct agents who are co-subjects in the creation of a mutual object. As such, writing and reading require a "pact of generosity" between the author and the reader.

"Thus," according to Sartre, "the author writes in order to address himself to the freedom of readers, and he requires it in order to make his work exist." 3 The writer, however, must also be respected by the reader. The writer "requires that (the reader] return this confidence he has given them, and that they recognise [the writer's] creative freedom."4 In order to successfully bring the work of art to completion, the reader, must sce the

${ }^{2}$ Ibid., p. 364.

3 Jean-Paul Sartre, What is Literature? and Other Essays, (Cambridge, Massachusetts: Harvard University Press, 1988), p. 58.

${ }^{4}$ lvid., p. 58. 
work as crafted by an author who has "introduced order where there was none" 5 and who serves as the reader's guide. It is the hope of the writer that the more the reader experiences his freedom in the act of reading, the more attuned the reader becomes to the freedom of the writer--the more the writer demands of the reader, the more the reader demands of him. 6

The novel completes itself only if the reader responds to the words in the book and projects an imaginary world of people and actions beyond them. The reader is solicited to perform the task of recomposing the "beautiful object beyond the traces left by the artist."7 The reader must "invent" the novel. For Sartre, reading presupposes the essentiality of both subject and the object. The object (in this case, the novel as produced by the writer) is essential because it is strictly transcendent; the novel imposes it's own structure and the reader must await its unfolding, even as he anticipates the action that is to come, and observe it. Correlatively, the reader is required to disclose or make the object appear and ensure that the object is produced, ${ }^{8}$ consumed and enjoyed.

Through reading, the reader animates the world of the object (i.e., the novel) which presents itself with a unique prefigured structure. In doing this the reader becomes aware of inhabiting the world of the novel and yet retains his awareness of himself as one who has chosen to animate it. Or, as Sartre puts it:

reading is creation, my freedom does not only appear to itself as pure autonomy but as creative activity, that is, it is not limited to giving itself its own law but perceives itself as being constitutive of the object. 9

This makes possible aesthetic enjoyment which requires that the reader be aware of both the object as object and of his own aesthetic accomplishment. If we do not preserve the world of the novel as ours, as one we inhabit, we cannot enjoy it, and yet if we do not preserve our constitutive role, we lose the enjoyment of creation. Thus aesthetic enjoyment is both engaged and creative: "it sustains the being of a world which is both its world and the 'external' world."10

This ability to preserve the constitutive roles that the reader-writer relation discloses is not peculiar to literature, or, indeed, to the activity of reading texts. The present phase of consciousness relates to the past

\footnotetext{
${ }^{5}$ lbid, p. 49.

${ }^{6}$ Ibid., p. 58.

${ }^{7}$ Ibid., p. 55.

${ }^{8}$ lbid., p. 52.

${ }^{9}$ lbid., p. 64.

${ }^{10}$ Ibid., p. 65.
} 
phases of itself as having been free yet, it also sees them as objects malleable for its present projects."1 The present phase engages in an activity akin to reading as it confronts and reactivates its past, which was authored by a previous phase. Sartre writes of the past phase: ' $m y$ ' past is first of all mine; that is, it exists as the function of a certain being which I am." 12 Just as the "being" of the present phase is to be free and spontaneous, so must the "being" of the past phase be seen as previously free and spontaneous, even though, from the stand-point of the present, it appears as an object devoid of freedom. Consequently the past phase was free and spontaneous and, as we describe this freedom, we ought to be able to reactivate it as such. As we shall show, Sartre's account of the nature of consciousness in Transcendence of the Ego precludes the possibility of this activity of reactivation in which the spontaneity of both the author and the past phase is preserved.

We begin by adumbrating Sartre's account of the nature of reflection and its implications for a theory of consciousness. Whenever we reflect on our conscious processes we find that the reflecting conscious process directs itself to the reflected-upon conscious process, which did not reflect on itself previously but was, instead, a straightforward consciousness of whatever. 13 Consciousness of itself as consciousness of its object can be both aware of its object and aware of itself without making itself into an object; that is, it is not objectivating itself. Each conscious process, whether reflective or not, is also conscious of itself as it is conscious of whatever. This consciousness (of) consciousness of whatever is the fundamental level of consciousness.14

Now, consciousness is initially not an object for itself; it is spontaneous in its intentionality and directed entirely toward the object of which it is conscious. There is no room for a substantial ego at this level because such an ego would introduce opacity into consciousness, thereby

${ }^{11}$ For reasons we develop later, Sartre explicates consciousness as being a unified stream of impersonal, non-egological, phases whose egoic structure, and, consequently, self, only appears in reflection. In order to conform to this description we use the phrase "phases of consciousness" to escape the implication that consciousness, as it acts, contains a substantial self who is independent of the process. Similarly, we shall use the phrase "partial extents" to indicate, for purposes of analysis, phases of consciousness which we can delimit and make salient in our reflective focusing.

${ }^{12}$ Sartre, Being and Nothingness, p. 110.

13 We have chosen to use the term "whatever" to indicate the object of consciousness in order to allow for the possibility of consciousness being aware of something and not objectivating it.

14 Jean-Paul Sartre, Transcendence of the Ego, (New York: Farrer, Straus \& Giroux, 1957, p. 40. 
destroying the essential spontaneity of consciousness. The two main problems to be confronted about this fundamental level of consciousness are: one, the explication of the way consciousness unifies itself into one conscious self and, two, how it can both view itself as an object for itself, a self or ego, and yet retain an awareness of itself as having been free.

Consciousness is able to unify itself because it is not unidimensional; rather, there is an on-going, automatic synthesis of the partial extent of consciousness as self-identical, as differentiated from each other, and as synthesised into one conscious life. This is made possible through the structuring of automatic awarenesses in each phase of consciousness such that each maintains itself as previously expected and as subsequently retained. In this way consciousness is automatically synthesising itself into one identical stream as it adverts from one thing to another and is thus busied.

Even if these automatic processes synthesise themselves, Sartre must still explain how reflection reveals the previous phase as having been both free and as having seen the act of a self. To account for this dimension of reflection, Sartre describes these automatic processes as non-positionally aware of themselves as they are actively engaged with whatever. ${ }^{15} \mathrm{He}$ writes:

For example, I am absorbed just now in my reading. I am going to try to remember the circumstances of my reading, my attitude, the lines that I was reading. I was thus going to revive not only these external details but a certain depth of unreflected consciousness, since the objects could only have been perceived by that consciousness and since they remain relative to it. That consciousness must not be posited as object of a reflection. On the contrary, I must direct my attention to the revived objects, but without losing sight of the unreflected consciousness, by joining in a sort of conspiracy with it and by drawing up an inventory of its content in a non-positional manner. There is no doubt about the result: while I was reading, there was consciousness of the book, of the heroes of the novel, but the I was not inhabiting this consciousness. It was only consciousness of the object and non-positional consciousness of itself. 16

15 By "non-positional" Sartre appears to mean consciousness does not objectivate whatever, nor does it believe or disbelieve in its object as existent; that is, it "suspends" its belief in the existence of whatever.

${ }^{16}$ Sartre, Transcendence of the Ego, Pp. 46-47. 
Sartre believes that this description of reading can serve as a paradigm for the possibility of the reactivation and identification of past phases in a subsequent reflection which retains an awareness of them as free. By thinking that the non-positional awareness of itself, as it acts, allows consciousness to preserve itself as a spontaneity, Sartre contends that he has enabled reflection to reveal past phases as objects, as free, and as mine. It is this last contention that we claim is untenable unless a further distinction is made.

His description, we argue, conflates non-positionality and nonobjectivity. Sartre has overlooked the fact that consciousness can be intending an object in either a positional, or in a non-positional way, and yet be positionally intending that which is not objectivated. For example, while reading I suspend my belief that this story is real or factual--its world is too cohesive, too beautiful, to be about my booming, buzzing and confusing world. Sartre has not, however, seen or allowed for the possibility that I will still be synthesising this partial extent of consciousness in identifying and differentiating syntheses which are positional. Unless they are positional they cannot be reactivated as ours because there is no basis for acknowledging them as ours. Regardless of its position with respect to the object, each partial extent always believes in itself with simple certainty; it posits itself as existing and as its own. If this non-reflective positional awareness of each partial extent were not taking place, then each phase of consciousness could not be retained and expected, retrotended and protended, as it was or will be. Nevertheless, Sartre, and we, want to claim that each is, was, or will be an impersonal spontaneity.

Thus, we need to distinguish positionality from objectivation in order to see how consciousness can be non-objectivating itself, or any other spontaneities, and still be positionally conscious of itself, or whatever, as believed in with certainty and as straight-forwardly accepted. Otherwise, in any present or subsequent phase of consciousness there would be no basis for accepting the spontaneity as mine, or perhaps, as yours. It is this distinction that makes possible Sartre's description of reading and the attendant aesthetic enjoyment; that is, that I can be both conscious of the object and conscious of myself as constitutive of the object. For this to be possible there cannot be a neutral non-positional stance towards consciousness as it is busied with the story, or else it would not be $m y$ aesthetic joy. As Sartre maintains, "the being which lives behind it is indeed its being and not another being." 17 Since this being is mine, it must have been identified as mine, as being positionally aware of itself as previously expected and subsequently retained as mine, and as spontaneous in its inception.

Having seen how the fundamental level of consciousness (of) consciousness of whatever, as it synthesises itself, does not doubt itself as a

17 Sartre, Being and Nothingness, p. 118. 
spontaneity we can generalise this description to cases of apprehending and interacting with other spontaneities. Consciousness has the ability to reflect and objectivate itself as the intentional object of my present, reflecting phase and grasp it in an automatic consciousness of whatever. As it can do this to itself, it can also, be automatically conscious of whatever in a positional, non-objectivating way, even as it is actively objectivating this same whatever.

A closer look at this phenomenon reveals the following as an example: As Roquentin looks at Anny as desirable he can also, be automatically aware of her gaze, be remembering what she said about wanting perfect moments and be expecting her to never again want to have such moments with him. These automatic conscious processes are being synthesised with the "present" phase of objectivating her as desirable, yet none of this requires that there be an ego that is doing all of this, only that the synthesising take place in order that in a subsequent phase consciousness could objectivate this phase and see it as its own. The part of the phase that was actively engaged in seeing her as desirable was given and retains an egoic quality by virtue of the positional non-objectivating consciousness which makes possible its being seen subsequently as having been engaged in by an ego. In this way, there can be consciousness of another as an object of my awareness and consciousness of it as one who is conscious of me as an object. Hence, it retains its freedom or spontaneity.

Returning now to the reader-writer relation, in which each subjectivity retains "creative" freedom, we can see how Sartre's description can be integrated with the above. As I read Nausea and find myself caught up wondering how to work through or eliminate the nausea I feel, as does Roquentin, I am carrying out the role Sartre required of me as a possible reader. In objectivating the novel and getting "caught up" in it, I can be automatically positionally conscious of Sartre as freely creating the novel and of guiding me throughrit. This latter automatic consciousness could be objectivated in a later phase of my conscious life and still I would automatically and positionally conscious of Sartre as the creative freedom who is responsible for Nausea.

Sartre saw this specific possibility for human interaction when he described the reader-writer relation in What is Literature? but failed to see that it can permeate all human interactions. In fact, Sartre's seminal description of the way consciousness appropriates its past phase as having been spontaneous makes possible the account of seeing another as both an object and as a spontaneity. As we have shown, however, he failed to adequately describe how consciousness can be positionally nonobjectivating itself or another. Consequently, Sartre's account of the loverbeloved relation was truncated since he failed to utilise the possibilities for human interaction he crystallises in What is Literature?

In conclusion, the pessimism in Being and Nothingness is unwarranted. By amending Sartre's description of the nature of 
consciousness we show that all human relationships are capable of objectivating whatever, thereby not depriving the object of its spontaneity. Yet, it can be conscious of whatever in an automatic non-objectivating manner which preserves the spontaneity which may be considered in the future. The lover-beloved relation described by Sartre in Being and Nothingness is a possible instance of human interaction. It, however, need not be the only one. The lover can appropriate the beloved as a freedom without the perpetual insecurity of losing his freedom. Conflict need not be the original meaning of being-for-others. 18

${ }^{18}$ A version of this paper was read at the Sartre Society, Canadian Division, Montreal, 1989. We would also like to thank Wendy Ewara for reading draft copies of this paper and for her insightful comments. 